\title{
Engel Analysis with Lorenz and Concentration Curves
}

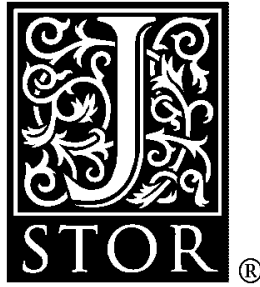

\author{
James R. Blaylock; David M. Smallwood
}

American Journal of Agricultural Economics, Vol. 64, No. 1. (Feb., 1982), pp. 134-139.

Stable URL:

http://links.jstor.org/sici?sici=0002-9092\%28198202\%2964\%3A1\%3C134\%3AEAWLAC\%3E2.0.CO\%3B2-U

American Journal of Agricultural Economics is currently published by American Agricultural Economics Association.

Your use of the JSTOR archive indicates your acceptance of JSTOR's Terms and Conditions of Use, available at

http://www.jstor.org/about/terms.html. JSTOR's Terms and Conditions of Use provides, in part, that unless you have obtained prior permission, you may not download an entire issue of a journal or multiple copies of articles, and you may use content in the JSTOR archive only for your personal, non-commercial use.

Please contact the publisher regarding any further use of this work. Publisher contact information may be obtained at http://www.jstor.org/journals/aaea.html.

Each copy of any part of a JSTOR transmission must contain the same copyright notice that appears on the screen or printed page of such transmission.

The JSTOR Archive is a trusted digital repository providing for long-term preservation and access to leading academic journals and scholarly literature from around the world. The Archive is supported by libraries, scholarly societies, publishers, and foundations. It is an initiative of JSTOR, a not-for-profit organization with a mission to help the scholarly community take advantage of advances in technology. For more information regarding JSTOR, please contact support@ jstor.org. 


\title{
Engel Analysis with Lorenz and Concentration Curves
}

\author{
James R. Blaylock and David M. Smallwood
}

Economic analysis of income transfer programs requires knowledge of how households with different incomes alter expenditure patterns as their incomes change. Classical demand theory, however, provides little guidance for quantifying these income response parameters. Consequently, researchers have relied on statistical approaches to find functional forms which "best"' describe the relationship between expenditures and income. The most commonly used specifications (linear, semilogarithmic, and double-logarithmic) imply that the Engel (expenditure) elasticities are monotonically increasing, decreasing, or constant across the income spectrum. However, serious errors may occur if actual elasticities do not adhere to one of these patterns.

This paper utilizes a nontraditional approach, based on income and expenditure distributions, to estimate expenditure elasticities. The method places less emphasis on the mathematical specification of the Engel relation and allows for increased flexibility in elasticity patterns. The primary purposes of this article are to examine household income and expenditure distributions in order to deduce the underlying Engel relationship and to measure inequality within each distribution. When other relevant factors (e.g., prices) are held constant, the expenditure distribution on a commodity is directly related to the income distribution via the commodity's Engel function.

A recently proposed technique for the estimation of Lorenz and concentration curves is employed (Kakwani and Podder). These curves are directly related to the cumulative distributions of income and expenditures. Expenditure elasticities and measures of income and expenditure inequality can be calculated from the estimated parameters of the Lorenz and concentration curves (Kakwani). Elasticities thus estimated are not constrained to be monotonic or constant across the income spectrum, and may vary across commodities.

Related objectives are to $(a)$ introduce a generalized functional form to describe the Lorenz and concentration curves, $(b)$ compare estimated expenditure elasticities among three urbanizations for several food groups using U.S. data, $(c)$ examine elasticity patterns within each urbanization, and $(d)$

\footnotetext{
James R. Blaylock and David M. Smallwood are with the U.S. Department of Agriculture, Economics and Statistics Service, National Economics Division.

The authors wish to thank Richard Haidacher, John Craven, and the Journal referees for helpful suggestions.

The views expressed in this paper are not necessarily those of USDA or ESS.
}

examine inequality of food expenditure and income distributions for each urbanization.

\section{Lorenz and Concentration Curves}

The Lorenz curve relates the cumulative proportion of total income received to the cumulative proportion of population units, with units arranged by ascending level of income. Concentration curves relate the cumulative proportion of economic variables other than income to the cumulative proportion of the population. ${ }^{1}$ Thus, other factors constant, the Lorenz and concentration curves are directly related to each other via the relationship between income and the economic variable of interest. For example, given the income distribution and the Engel function for a particular commodity, one can easily derive the expenditure distribution for the commodity. Likewise, given the concentration curve for expenditures on a commodity and the Lorenz curve, one can derive the implied Engel function. The derivation of this relationship, using elasticities, is the subject of this section.

Mathematically, Lorenz and concentration curves can be expressed conveniently in terms of the probability distribution function (PDF) and the first moment distribution function (FMDF) of income and expenditures, respectively. Assuming that per capita income, $Y$, is randomly distributed with probability density function $f(Y)$, and mean $\mu$, then the PDF of income is defined as

$$
F(Y)=\int_{0}^{Y} f(y) d y
$$

and represents the proportion of the population units having income less than or equal to $Y$. The FMDF of $Y$ is defined as

$$
F_{1}(Y)=(1 / \mu) \int_{0}^{Y} y f(y) d y
$$

and represents the proportion of total income received by population units having total income less than or equal to $Y$.

The relationship between $F(Y)$ and $F_{1}(Y)$ is called the Lorenz curve. A typical Lorenz curve is $A B C$ in figure 1. The segment $A D C$, defined by $F(Y)=$ $F_{1}(Y)$, is called the egalitarian line and represents

\footnotetext{
1 This definition of concentration curves (Kakwani and Podder) differs from the traditional definition by requiring an ordering of the population units by income rather than the economic variable of interest.
} 
the special case of a uniform and equal income distribution across the population units. The extent to which the Lorenz curve deviates from the egalitarian line indicates the degree of income inequality.

A concentration curve is similar to a Lorenz curve. Assuming $v_{i}(Y)$ to be the implied but unknown Engel relation for the $i$ th commodity and $\mu_{i}$ to be the expenditure mean, then the $F M D F$ for expenditure on the $i$ th commodity,

$$
F_{1}\left[v_{i}(Y)\right]=\left(1 / \mu_{i}\right) \int_{0}^{Y} v_{i}(y) f(y) d y,
$$

is the proportion of per capita expenditure on the commodity by population units having total income less than or equal to $Y$. The concentration curve for the $i$ th commodity is defined by the relationship between $F(Y)$ and $F_{1}\left[v_{i}(Y)\right]$.

To facilitate estimation, coordinates of the Lorenz and concentration curves are redefined using a method outlined by Kakwani and Podder. This new coordinate system defines the curves in relation to the egalitarian line. Specifically, let $B$ be any point on the Lorenz curve with coordinates $\left[F(Y), F_{1}(Y)\right]$ and define new coordinates,

$$
\begin{aligned}
& \theta=\left[F(Y)+F_{1}(Y)\right] / \sqrt{2} \text { and } \\
& \Phi=\left[F(Y)-F_{1}(Y)\right] / \sqrt{2} .
\end{aligned}
$$

Hence, $\theta$ represents the length of the line segment $A D$ from the origin along the egalitarian line and $\Phi$ represents the length of the line segment $B D$ from $B$ to the egalitarian line. This coordinate system reflects a 45-degree clockwise rotation of figure 1 .

The equation of the Lorenz curve in terms of $\Phi$ and $\theta$ can be written as

$$
\Phi=g(\theta),
$$

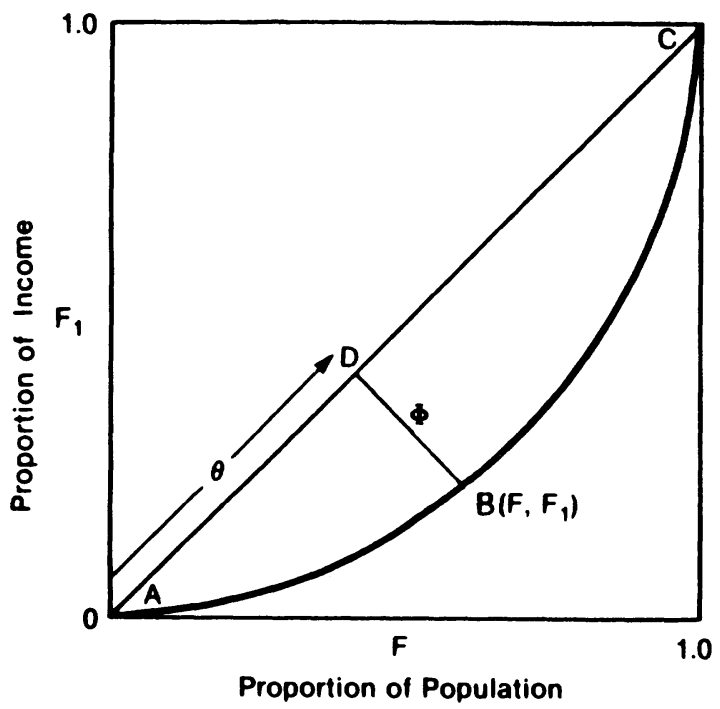

Figure 1. Lorenz curve where $\theta$ varies from zero to $\sqrt{2}$. The first and second derivatives of $\Phi$ with respect to $\theta$ are

$$
\begin{aligned}
& g^{\prime}(\theta)=(\mu-Y) /(\mu+Y) \text { and } \\
& g^{\prime \prime}(\theta)=-(2 \sqrt{2}) \mu^{2} /\left[f(Y)(\mu+Y)^{3}\right] .
\end{aligned}
$$

The same coordinate transformation for the concentration curves is

$$
\begin{aligned}
\theta_{i} & =\left\{F(Y)+F_{1}\left[v_{i}(Y)\right]\right\} / \sqrt{2} \text { and } \\
\Phi_{i} & =\left\{F(Y)-F_{1}\left[v_{i}(Y)\right]\right\} / \sqrt{2} .
\end{aligned}
$$

The general form of the concentration curve for the $i$ th commodity in terms of the new coordinates is

$$
\Phi_{i}=g_{i}\left(\theta_{i}\right),
$$

with first and second derivatives defined by

$$
\begin{aligned}
g_{i}^{\prime}\left(\theta_{i}\right)=\left[\mu_{i}-v_{i}(Y)\right] /\left[\mu_{i}+v_{i}(Y)\right] \text { and } \\
g_{i}^{\prime \prime}\left(\theta_{i}\right)=[-2 / \sqrt{2}]\left[\mu_{i}^{2} v_{i}^{\prime}(Y)\right] / \\
\quad\left[f(Y)\left\{\mu_{i}+v_{i}(Y)\right\}^{3}\right] .
\end{aligned}
$$

The expenditure elasticity for the $i$ th commodity is defined as

$$
\eta_{i}=\left(\partial E_{i} / \partial Y\right)\left(Y / E_{i}\right),
$$

where $E_{i}$ is expenditure and $Y$ denotes income. Using this definition and equations (6), (7), (10), and (11), the expenditure elasticity for the $i$ th commodity (in terms of the Lorenz and concentration curves) is

(12) $\eta_{i}=\frac{\left\{g^{\prime \prime}{ }_{i}\left(\theta_{i}\right)\left[1+g^{\prime}(\theta)\right]^{2}\left[\left(1-g^{\prime}(\theta)\right]\right\}\right.}{\left\{g^{\prime \prime}(\theta)\left[1+g^{\prime}{ }_{i}\left(\theta_{i}\right)\right]^{2}\left[1-g^{\prime}{ }_{i}\left(\theta_{i}\right)\right]\right\}}$.

If data on per capita expenditure for the $i$ th commodity are grouped by income class, then equation (12) can be used to compute expenditure elasticities at the end points of each class (Kakwani). In this analysis the elasticities derived using the above procedures are conditioned on income and urbanization. The effect of other variables is assumed to be minimal. However, this kind of analysis can be extended to other possible determinants of food expenditures such as race or region by data disaggregation.

An additional benefit of this approach is that measures of income and expenditure inequality can be calculated conveniently using the estimated parameters of the Lorenz and concentration curves.

The most frequently used measure of inequality is the Gini coefficient. The Gini coefficient measures the departure of the Lorenz (or concentration) curve from the egalitarian line. It is the ratio of the area between the egalitarian line and the Lorenz (or concentration) curve and the total area under the egalitarian line. Since the area under the egalitarian line is $1 / 2$, this ratio is equal to twice the area between the Lorenz curve and the egalitarian line. In terms of the translated coordinate system, the Gini coefficient for income (or expenditures) is 


$$
G C=2 \int_{0}^{\sqrt{2}} g(\theta) d \theta .
$$

The indices may vary between 0 and 1 for income and between -1 and 1 for expenditure. Negative Gini ratios result from negative expenditure elasticities; the concentration curve lies above the egalitarian line because expenditures are higher at lower incomes than at higher incomes. A Gini coefficient of zero indicates perfect equality of income (or expenditures). A coefficient of one (or minus one for expenditures) reveals total inequality. In this paper, the Gini coefficients are calculated using Simpson's rule for numerical integration.

\section{Model Development}

Equations of Lorenz and concentration curves have been derived traditionally from density functions of income and expenditure distributions, respectively, usually with poor results (Kakwani and Podder). The coordinate system illustrated in the previous section provides the basis for direct estimation of the Lorenz and concentration curves, once their mathematical form is specified. Then, from the estimated parameters of the Lorenz and concentration curves, corresponding expenditure elasticities and Gini coefficients can be calculated.

Kakwani and Podder propose a functional specification for describing relationships $g(\theta)$ and $g_{i}\left(\theta_{i}\right)$ based on a modified Beta function. The Box-Cox (B-C) model we propose includes the Kakwani and Podder (K-P) function as a special case and gives a better fit to the data (Box and Cox).

The K-P function for the Lorenz curve is

$$
\text { (14) } \ln (\Phi)=A+\alpha \ln (\theta)+\beta \ln (\sqrt{2}-\theta)+e \text {, }
$$

where $A, \alpha$, and $\beta$ are parameters to be estimated and $e$ is the equation error term. This general model also applies to concentration curves. Equation (14) can be estimated by ordinary least squares.

The Box-Cox transformation for any positive variable $W$ is defined as

$$
\begin{array}{rlrl}
W^{(\gamma)} & =\left(W^{\gamma}-1\right) / \gamma, & \gamma \neq 0 \\
& =\ln (W) \quad, \quad \gamma \rightarrow 0,
\end{array}
$$

where $\gamma$ is an unknown parameter. The model we propose for estimating the Lorenz curve is

$$
\Phi^{(\lambda)}=A^{*}+\alpha^{*} \theta^{(\nu)}+\beta^{*}(\sqrt{2}-\theta)^{(\delta)}+u,
$$

where $\lambda, \nu, \delta, A^{*}, \alpha^{*}$, and $\beta^{*}$ are parameters and $u$ is the error term. Equation (16) asymptotically approaches the corresponding K-P function as all transformation parameters approach zero. Thus, the B-C function allows added flexibility in determining the appropriate degree of nonlinearity. The same functional specification as in equation (16) is used for estimating concentration curves.

Equation (16) is nonlinear in the parameters and is estimated via maximum likelihood techniques.

The likelihood function, assuming a normally distributed error term with zero mean and constant variance, is

$$
\begin{aligned}
L= & \prod_{j=1}^{N}\left[1 /\left(2 \pi \sigma^{2}\right)^{\frac{1}{2}}\right]^{N} \exp \left\{-\left(1 / 2 \sigma^{2}\right)\left[\Phi_{j}^{(\lambda)}\right.\right. \\
& \left.\left.-A^{*}-\alpha^{*} \theta_{j}^{(\nu)}-\beta^{*}\left(\sqrt{2}-\theta_{j}\right)^{(\delta)}\right]^{2}\right\}|J|,
\end{aligned}
$$

where $|J|$, the Jacobian of the inverse transformation from $\Phi_{j}^{(\lambda)}$ to $\Phi_{j}$, is equal to $\prod_{j=1}^{N} \Phi_{j}^{\lambda-1}$ and the product, $\Pi$, is calculated over all observations, $N$. After logarithmic transformation of equation (17), consistent and asymptotically efficient estimates of the parameters can be obtained via a nonlinear maximum likelihood algorithm. ${ }^{2}$ The likelihood functions of the concentration curves can be derived similarly.

\section{Data}

The 1972-74 Consumer Expenditure Diary Survey (CEDS), compiled by the Bureau of Labor Statistics, is the source of data for this analysis. Since the CEDS survey covered a period of rapidly rising food prices, only the first year of the survey was used in an attempt to lessen price effects. However, within each year, the survey sample is nationally representative. These data were obtained from a cross-section of U.S. households reporting detailed information on purchases during a two-week period together with socioeconomic data concerning the household units. Prior to this study, this data was extensively examined for reporting and coding errors and was edited into a convenient format (Buse, Mann, Salathe).

The CEDS sample was partitioned into three mutually exclusive and exhaustive urbanization categories. These three subgroups are defined as (a) SMSA-population of 50,000 or more; (b) URBAN-population of between 10,000-50,000; and $(c)$ RURAL-population of less than 10,000 . Separate analyses were performed on each urbanization category.

Annual income from all sources and weekly expenditures for food at home and away from home were used to analyze food expenditure/income distributional relationships. Income and expenditures are expressed on a per capita basis to adjust for differences in family size and then aggregated into population percentiles arranged by income.

\footnotetext{
${ }^{2}$ Approximate asymptotic standard errors of the parameters from the B-C model are obtained from the negative of the inverse matrix containing the second partial derivatives of the likelihood function. The standard errors reported in this paper are approximate because it is not possible to compute the expected value of the elements in the information matrix. Hence, care should be taken in the interpretation of $t$-tests. The Davidon-Fletcher-Powell algorithm (see Powell) was used.
} 


\section{Empirical Results}

Parameter estimates and approximate standard errors for both the K-P and B-C specifications of the transformed Lorenz and concentration curves are reported in table 1 . Only the SMSA results are included. ${ }^{3}$

The likelihood ratio test is used to compare the $\mathrm{K}-\mathrm{P}$ specification with the more flexible B-C extension. This test is appropriate since the two models are nested: the K-P function is a special case of the B-C model when $\lambda, \nu$, and $\delta$ are zero. The test statistic, -2 times the logarithm of the likelihood ratio (defined as the ratio of the restricted [K-P] to the unrestricted [B-C] likelihood function), is asymptotically distributed as a chi-square random variable. Its degrees of freedom correspond to the number of independent parametric restrictions (three in this case) used to obtain the reduced or restricted model. Evaluation of the K-P and B-C functions involves comparing the calculated test statistics with tabulated values of the chi-square variable at the 0.01 significance level. The restricted specification is rejected for large values of the calculated test statistic.

The likelihood ratio test statistics are reported in table 2. The test results indicate that the B-C model provides a significant statistical improvement over the K-P model for all estimated Lorenz and concentration curves. Both the $\mathrm{B}-\mathrm{C}$ and $\mathrm{K}-\mathrm{P}$ models provide a good fit. However, the $\mathrm{B}-\mathrm{C}$ model with its added flexibility performs better.

Expenditure elasticities by urbanization and in-

${ }^{3}$ Parameter estimates for all models discussed in this paper and an analysis for nine major food groups are available from the authors. come are presented graphically in figures 2 and 3 for the food-at-home and food-away-from-home categories. ${ }^{4}$ Illustrated in these figures are some of the diverse elasticity relationships that this model is capable of producing. These relationships may be increasing, decreasing, relatively constant, or nonmonotonic across the income spectrum.

Elasticity patterns vary considerably across urbanizations and within each urbanization. The urban food-at-home elasticity increases up to about the $\$ 1,500$ per capita income level and then monotonically declines. The rural and SMSA food-athome elasticities increase gradually with income. The food-away-from-home elasticities for these two urbanizations increase monotonically but at a faster rate than the food-at-home elasticities. The foodaway-from-home elasticities for the rural and SMSA groups are smaller across the entire income spectrum than the corresponding elasticities for the urban group. In general, it appears that urban and SMSA residents have a larger elasticity across the entire income spectrum for food away from home than do their rural counterparts. The opposite is true of food at home for per capita incomes of $\$ 3,000$ or more. This may be influenced by location and travel considerations.

In summary, considerable variation exists in the way residents of different urbanizations (and at different income levels within a given urbanization) allocate additional dollars of income for food at home and food away from home.

The Gini coefficients as calculated from the actual observations and those estimated from the pa-

\footnotetext{
${ }^{4}$ It is complex to calculate even approximate standard errors for elasticities in this highly nonlinear model. Hence, we do not test for statistical differences in elasticities across urbanizations.
}

Table 1. Estimated Parameters for K-P and B-C Models, SMSA

\begin{tabular}{|c|c|c|c|c|c|c|c|}
\hline \multirow[b]{2}{*}{ Curve (K-P) } & \multicolumn{6}{|c|}{ Parameters } & \multirow{2}{*}{$\begin{array}{l}\text { Log-Likelihood } \\
\text { Value }\end{array}$} \\
\hline & $A$ & $\alpha$ & $\beta$ & $\lambda$ & $\nu$ & $\delta$ & \\
\hline Lorenz & $\begin{array}{c}0.3755 \\
(0.0007)^{\mathrm{a}}\end{array}$ & $\begin{array}{c}0.8531 \\
(0.0014)\end{array}$ & $\begin{array}{c}0.8508 \\
(0.0019)\end{array}$ & 0.0 & 0.0 & 0.0 & 628.83 \\
\hline Food at home & $\begin{array}{c}0.0607 \\
(0.0009)\end{array}$ & $\begin{array}{c}0.8211 \\
(0.0125)\end{array}$ & $\begin{array}{c}0.7087 \\
(0.0114)\end{array}$ & 0.0 & 0.0 & 0.0 & 603.89 \\
\hline \multirow[t]{2}{*}{ Food away from home } & $\begin{array}{c}0.3418 \\
(0.0029)\end{array}$ & $\begin{array}{c}0.9273 \\
(0.0064)\end{array}$ & $\begin{array}{c}0.9210 \\
(0.0077)\end{array}$ & 0.0 & 0.0 & 0.0 & 511.33 \\
\hline & \multicolumn{6}{|c|}{ Parameters } & \\
\hline Curve (B-C) & $A^{*}$ & $\alpha^{*}$ & $\beta^{*}$ & $\lambda$ & $\nu$ & $\delta$ & \\
\hline Lorenz & $\begin{array}{c}-1.2027 \\
(0.0616)\end{array}$ & $\begin{array}{c}0.8894 \\
(0.0245)\end{array}$ & $\begin{array}{c}0.9101 \\
(0.0265)\end{array}$ & $\begin{array}{c}-0.1981 \\
(0.0640)\end{array}$ & $\begin{array}{c}-0.2063 \\
(0.0510)\end{array}$ & $\begin{array}{c}-0.1788 \\
(0.0500)\end{array}$ & 718.34 \\
\hline Food at home & $\begin{array}{c}-1.5367 \\
(0.0678)\end{array}$ & $\begin{array}{c}0.3474 \\
(0.0300)\end{array}$ & $\begin{array}{c}0.3017 \\
(0.0424)\end{array}$ & $\begin{array}{c}0.4410 \\
(0.1493)\end{array}$ & $\begin{array}{c}0.4400 \\
(0.1371)\end{array}$ & $\begin{array}{c}0.3509 \\
(0.0806)\end{array}$ & 610.49 \\
\hline Food away from home & $\begin{array}{c}-1.0915 \\
(0.1487)\end{array}$ & $\begin{array}{c}0.6519 \\
(0.0200)\end{array}$ & $\begin{array}{c}0.6436 \\
(0.0173)\end{array}$ & $\begin{array}{c}0.1409 \\
(0.0504)\end{array}$ & $\begin{array}{c}0.0123 \\
(0.1439)\end{array}$ & $\begin{array}{c}0.0060 \\
(0.0147)\end{array}$ & 577.44 \\
\hline
\end{tabular}

a Values in parentheses are asymptotic standard errors. 
Table 2. Chi-square Test Results, K-P Model versus B-C Model

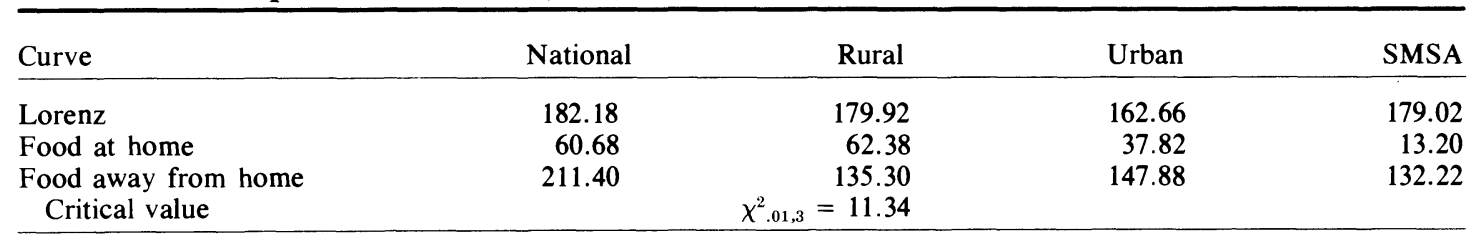

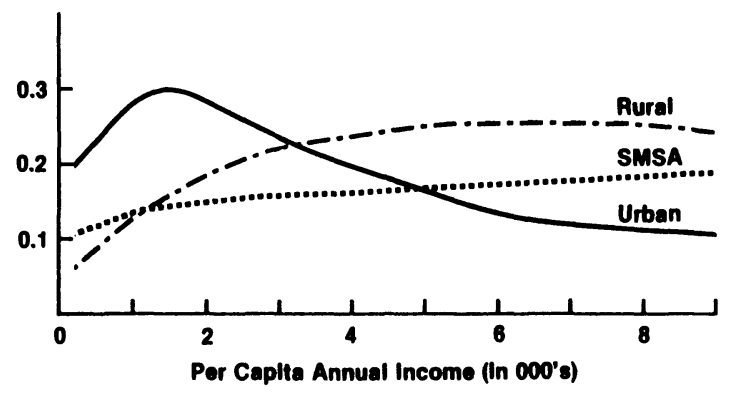

Figure 2. Expenditure elasticities, food at home elasticity

rameters of the B-C curves are presented in table 3 . The Gini coefficients estimated from the B-C models are quite close to actual values in all cases. This indicates that the B-C curves gave a very good fit.

In all urbanizations, according to the Gini coefficients, income displayed the largest inequality and food-at-home expenditures showed the least. Food-away-from-home expenditures were almost

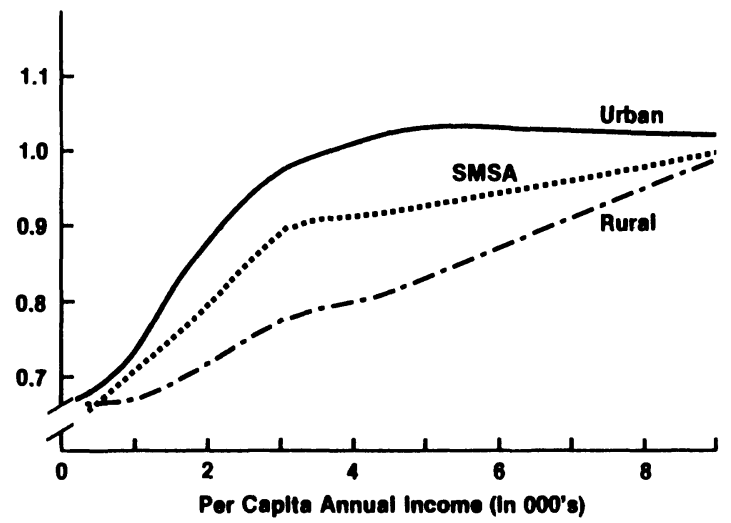

Figure 3. Expenditure elasticities, food away from home elasticity as unequally distributed as income. Inequality in the distributions of income and food-at-home expenditure appear to be approximately the same across each urbanization. Food-away-from-home expenditures were more equally distributed in the SMSA and rural groups than in the urban section.

Percentage shares of income and expenditures as calculated from the actual data and $\mathrm{B}-\mathrm{C}$ curves are presented in table 4 . The estimated and actual shares are very close in most instances. This provides further evidence to validate the fit of the B-C model. The share $\mathrm{rf}$ income received by the poorest $5 \%$ of the total population was approximately $0.6 \%$ and was lower than the percentage share of expenditures for any of the food groups. Conversely, the shares of income and food-away-from-home expenditures for the richest $5 \%$ of the population were approximately $19 \%$ and $16 \%$, respectively. Further comparisons of percentage shares of income and expenditures received by various population subsets within and across urbanizations are possible with the data in table 4 .

\section{Conclusions}

This paper has shown that elasticity patterns (as income increases) can be diverse and nonmonotonic. The patterns found in this analysis could not be obtained from traditional methods of Engel analysis.

Gini coefficients indicated that income and foodaway-from-home expenditures were distributed more unequally across population groups than food-at-home expenditures. Also, food away from home was found to be more unequally distributed within the urban group than within either the rural or SMSA groups. Conversely, the percentage shares of income and food-at-home expenditures by the poorest segments of the population did not vary

Table 3. Gini Coefficients, Actual from Observations and Predicted from B-C Model

\begin{tabular}{|c|c|c|c|c|c|c|c|c|}
\hline & \multicolumn{2}{|c|}{ National } & \multicolumn{2}{|c|}{ Rural } & \multicolumn{2}{|c|}{ Urban } & \multicolumn{2}{|c|}{ SMSA } \\
\hline & Actual & Predicted & Actual & Predicted & Actual & Predicted & Actual & Predicted \\
\hline Income & 0.4120 & 0.4122 & 0.4171 & 0.4236 & 0.4134 & 0.4141 & 0.4086 & 0.4084 \\
\hline Food at home & 0.0765 & 0.0765 & 0.0817 & 0.0823 & 0.0869 & 0.0869 & 0.0723 & 0.0725 \\
\hline Food away from home & 0.3654 & 0.3655 & 0.3584 & 0.3585 & 0.4098 & 0.4096 & 0.3460 & 0.3460 \\
\hline
\end{tabular}


Table 4. Percentage Shares of Income and Expenditures as Calculated from Actual Data and B/C Model

\begin{tabular}{|c|c|c|c|c|c|c|c|c|}
\hline & \multicolumn{2}{|c|}{ National } & \multicolumn{2}{|c|}{ Rural } & \multicolumn{2}{|c|}{ Urban } & \multicolumn{2}{|c|}{ SMSA } \\
\hline & Actual & Predicted & Actual & Predicted & Actual & Predicted & Actual & Predicted \\
\hline \multicolumn{9}{|l|}{ Income } \\
\hline Poorest 5\% & 0.5777 & 0.5773 & 0.5213 & 0.5216 & 0.6329 & 0.6322 & 0.6143 & 0.6145 \\
\hline Poorest $10 \%$ & 1.7212 & 1.7439 & 1.6111 & 1.6148 & 1.9021 & 1.9028 & 1.8089 & 1.8100 \\
\hline Richest $5 \%$ & 19.3602 & 19.3687 & 19.3503 & 19.3517 & 20.0332 & 20.0475 & 19.3537 & 19.3467 \\
\hline Richest $10 \%$ & 29.9639 & 30.0011 & 29.4081 & 29.4100 & 30.0192 & 30.0203 & 29.9028 & 29.9181 \\
\hline \multicolumn{9}{|l|}{ Food at home } \\
\hline Poorest 5\% & 4.0236 & 3.9425 & 4.1311 & 4.1481 & 3.4440 & 3.2335 & 3.9888 & 3.8792 \\
\hline Poorest $10 \%$ & 8.0371 & 7.9749 & 8.1347 & 8.4571 & 7.0104 & 7.0698 & 7.9282 & 8.1191 \\
\hline Richest $5 \%$ & 6.7541 & 6.7027 & 7.1906 & 6.8130 & 6.9163 & 6.5373 & 6.5825 & 6.7975 \\
\hline Richest $10 \%$ & 12.7631 & 12.7676 & 12.9872 & 12.9416 & 11.8837 & 12.4169 & 12.5683 & 12.8878 \\
\hline \multicolumn{9}{|c|}{ Food away from home } \\
\hline Poorest $5 \%$ & 1.3315 & 1.1788 & 1.5140 & 1.1335 & 1.3202 & 1.2184 & 1.4348 & 1.3725 \\
\hline Poorest $10 \%$ & 2.6376 & 2.7168 & 2.9134 & 2.2855 & 2.2925 & 2.2855 & 2.9007 & 3.0407 \\
\hline Richest $5 \%$ & 16.2458 & 16.2327 & 20.1745 & 19.6513 & 20.2452 & 21.1928 & 15.8272 & 15.6589 \\
\hline Richest $10 \%$ & 27.2676 & 27.2958 & 28.4696 & 28.6535 & 33.2497 & 32.8396 & 26.1645 & 26.0372 \\
\hline
\end{tabular}

substantially across urbanizations. The same was true for the richest population subsets.

In summary, several conclusions can be drawn. First, traditional methods for estimating Engel parameters do not allow the flexibility necessary to characterize the varied elasticity patterns that were found in this study. This is important for policy analysis involving the impact of income transfer programs on population subgroups located at the extremes of the income distribution.

Second, procedures outlined in this paper can yield information not directly obtainable from more traditional methods of Engel analysis. For example, Gini coefficients and income and expenditure shares are easy to calculate.

Finally, the B-C model, while more complicated to estimate, is a significant improvement over the $\mathrm{K}-\mathrm{P}$ function, especially in the tails of the distribution, for estimating Lorenz and concentration curves.

[Revision July 1980; revision accepted June 1981.]

\section{References}

Box, G. E. P., and D. R. Cox. "An Analysis of Transformations." J. Royal Statist. Soc., ser. B, 26(1964):211-43.

Buse, R. C., J. S. Mann, and L. Salathe. Data Problems in the 1972-1974 BLS Diary Survey Public Use Tapes. Dep. Agr. Econ. Staff Pap. No. 152, University of Wisconsin, 1978.

Consumer Expenditure Survey: Diary Survey, July 1972June 1974. Washington, D.C.: U.S. Bureau of Labor Statistics Bull. No. 1959, 1977.

Kakwani, N. "A New Method for Estimating Engel Elasticities." J. Econometrics 8(1978):103-10.

Kakwani, N., and N. Podder. "Efficient Estimation of the Lorenz Curve and Associated Inequality Measures from Grouped Observations." Econometrica 44(1976): 137-48.

Powell, M. J. D. "Recent Advances in Unconstrained Optimization." Math. Programming 1(1971):26-57. 